\title{
Dentinogenesis imperfecta type 3
}

INSERM

\section{Source}

INSERM. (1999). Orphanet: an online rare disease and orphan drug data base.

Dentinogenesis imperfecta type 3. ORPHA:166265

Dentinogenesis imperfecta type $3(\mathrm{DGl}-3)$ is a rare, severe form of dentinogenesis imperfecta ( $D G l$, see this term) characterized by opalescent primary and permanent teeth, marked attrition, large pulp chambers, multiple pulp exposure and shell teeth radiog raphically (i.e. teeth which appear hollow due to dentin hypotrophy). 